\title{
Rhinosporidiosis-Retrospective Analysis of Cases Presenting in a Tertiary Medical College Hospital in Ernakulam
}

\author{
Sabu A.N. ${ }^{1}$ \\ ${ }^{1}$ Department of ENT, Government Medical College, Ernakulam, Kerala, India.
}

\section{ABSTRACT}

\section{BACKGROUND}

Rhinosporidiosis is a chronic granulomatous disease caused by the eukaryotic organism, Rhinosporidium seeberi affecting humans and animals. This disease is endemic in several parts of South Asia. The principal purpose of this study was to assess the clinical features of rhinosporidiosis and the demographic profile of the disease in the Ernakulam district. The role of predisposing factors like bathing in ponds, nose-picking habits and the postoperative recurrence rate in the patients were also studied.

\section{METHODS}

This retrospective record-based study was conducted in a tertiary care centre in Ernakulam district of Kerala, India, from January 2014 to June 2016. Clinicopathological profile, demographic data of the patients including their area of residence were retrieved from the records. All patients underwent routine haematological investigation and nasal endoscopy. All rhinosporidial masses were excised and their base cauterised under general anaesthesia, with the aid of endoscope. All patients were given dapsone for 6 months. All cases were followed up for a one-year postoperative period. The retrospective data obtained were entered in Microsoft Excel spreadsheet and analysed

\section{RESULTS}

The patients in the series were between 14 to 60 years of age. There were 12 male and 3 female patients. Most patients came from the urban areas of the Ernakulam district. The main symptoms were nasal obstruction, epistaxis and nasal mass. The nose and nasopharynx were the commonest sites involved. The inferior meatus and floor of the nasal cavity were the common sites of attachment. Most of the nasal masses were pedunculated and multiple. Recurrent cases, which had previously been operated elsewhere formed the majority in the case series. None of the operated cases in the series showed recurrence during one year follow up. Most cases were associated with the $0+$ blood group. Nasal synechia was the most common sequelae of repeated surgeries.

\section{CONCLUSIONS}

This study revealed the endemic nature of this disease in Ernakulam and surrounding districts. The results showed the disease was associated more with the male gender, the young, bathing in stagnant water and the 0+ blood group. Most of the cases came from an urban background. The study showed the complications of recurrent surgeries and the need for careful removal of the rhinosporidial masses under general anaesthesia. It also emphasises the need for educating the general public against bathing in contaminated water bodies.

\section{KEY WORDS}

Rhinosporidiosis, Rhinosporidium, Epidemiology, Recurrence, Retrospective Studies

\author{
Corresponding Author: \\ Dr. Sabu A.N., \\ Assistant Professor, \\ Department of ENT, \\ Government Medical College, \\ Ernakulam, Kerala, India. \\ E-mail:drsabu.an@gmail.com
}

DOI: $10.14260 /$ jemds/2022/48

How to Cite This Article:

Sabu AN. Rhinosporidiosis-retrospective analysis of cases presenting in a tertiary medical college hospital in Ernakulam. J Evolution Med Dent Sci 2022;11(01):253258, DOI: $10.14260 / \mathrm{jemds} / 2022 / 48$

Submission 11-01-2022,

Peer Review 25-01-2022,

Acceptance 29-01-2022,

Published 31-01-2022.

Copyright (c) 2022 Sabu A.N. This is an open access article distributed under Creative Commons Attribution License [Attribution 4.0 International (CC BY 4.0)] 


\section{BACKGROUND}

Rhinosporidiosis is a chronic granulomatous disease commonly affecting the mucous membranes of the nose, nasopharynx, laryngopharynx and eye. The disease is endemic in South Asia, with the majority of the cases being reported from Southern India and Srilanka. ${ }^{1}$ Few sporadic cases have also been reported from around the world, probably due to the increased number of migration of people from endemic areas to these non-endemic regions.

The causative organism for rhinosporidiosis is Rhinosporidium seeberi, which is now regarded as belonging to a group of fish parasite DRIP clade located between the animal and fungal divergence. ${ }^{2}$ The probable mode of infection from the natural aquatic habitat of Rhinosporidium seeberi is through the traumatised epithelium, most commonly in the nasal cavity. ${ }^{3}$

The disease has been isolated from humans as well as animals like cattle, horses etc. Four clinical forms of rhinosporidiosis have been described: nasal, ocular, cutaneous, and disseminated form are the four clinical forms of rhinosporidiosis described. The commonest site of infection is in the upper respiratory tract, notably the anterior nasal cavity, the inferior turbinate, septum and floor. Nasal rhinosporidiosis usually presents, with spontaneous unprovoked epistaxis as the only symptom in the early stages. On examination, the rhinosporidial mass appears as a pedunculated mass which is granular, and red in colour due to increased vascularity. The surface contains greyish spots representing mature sporangia. The diagnosis is usually clinical but definitive diagnosis is by histopathological examination. ${ }^{3}$

The immune mechanism in humans is stimulated by R.seeberi. But it evades the host's immunity through the mechanisms of immune suppression, immune distraction, immune deviation, and binding of host immunoglobulins. This attributes to the chronicity, recurrence and dissemination of the disease condition. 4,5

The treatment of choice for rhinosporidiosis is wide local excision of the lesion and cauterisation of the base. Laser, harmonic scalpel and coblation are being increasingly used in the management of this condition. Though chemotherapy is often not very useful, dapsone is found to be of some effect in this disease. 6

The disease, though non-fatal, is notorious for recurrence with the need for multiple surgeries. Epidemiological surveys in collaboration with multidisciplinary teams (including medical, veterinary and microbiology experts) will help in understanding more about the natural course of the disease and may help to reduce the high prevalence of this disease in our state.

Ernakulam situated on the banks of Vembanad -the largest freshwater lake in the state of Kerala, abounds in water bodies including ponds, rivers, temple tanks and reservoirs. The city derives its name from the temple pond (Rishinagakulam) of the Ernakulam shiva temple. Ashworth and Logan Turner observed nearly a hundred years back that "a number of recorded cases of Rhinosporidum has come from this district". ${ }^{7}$ However, till date no studies have been done from the district detailing the demographic distribution of the cases.
The principal purpose of this study was to assess the clinical features of rhinosporidiosis and the demographic profile of the disease in the Ernakulam district. The role of predisposing factors like bathing in ponds, nose-picking habits and the postoperative recurrence rate in the patients were also studied.

\section{METHODS}

This retrospective record-based study was conducted in a tertiary care centre in Ernakulam district of Kerala, India from January 2014 to June 2016. According to the departmental statistics of the five years preceding the study, an average of 5 cases of rhinosporidiosis were operated in the department per year.

All 15 histologically proven cases of rhinosporidiosis who were surgically treated in the department of ENT, Government Medical College, Ernakulam, Kerala during the 2.5-year period were included in the study after getting approval from the Institutional Ethics Committee.

Clinicopathological profiles, demographic data of the patients including their area of residence were retrieved from the records. The missing data in the records were collected by telephonic interview. All routine haematological investigations including blood groups were done for the patient. All patients had undergone diagnostic nasal endoscopy at the time of admission to find out the site and extent of lesions. All nasal and nasopharyngeal lesions underwent excision and cauterisation of the base of the lesion under visualisation of nasal endoscope under general anaesthesia. The surgically removed specimens were sent for histopathological examination. All the patients were given dapsone 6 months postoperatively. All these patients had been followed up for 12 months and were subjected to clinical examination and diagnostic nasal endoscopy at regular intervals of 1 month, 3 months, 6 months and at the end of 1 year.

\section{Statistical Analysis}

The retrospective data obtained were entered in Microsoft Excel spreadsheet and analysed. The frequency and percentage were noted.

\section{RESULTS}

There were 12 males (80\%) and 3 females (20\%) in the study. Age distribution varied from 14 years to 60 years with predominance in the age groups of 21-30 and 31-40-years. As seen in Table: 1 , the disease was commoner among the males in the age groups of $11-20$ and $21-30$ years, who formed $40 \%$ ( 6 cases) of the study population. $66.67 \%$ (2 cases) of the female cases in the series belonged to the age group 31-40 years.

As shown in Table: 1, the majority of the rhinosporidosis cases $(8 ; 53.33 \%)$ in this series came from urban areas, while rural areas contributed only to $40 \%$ (6) of cases. Semiurban areas contributed $6.67 \%$ (1) of the total cases in the series. 
As can be seen in Table: 1 and Figure:1, the majority of these cases were reported from Ernakulam district (8;53.33\%). Among the 7 taluks in Ernakulam district, only 3 taluks- Kochi $(3 ; 20 \%)$, Paravoor $(3 ; 20 \%)$, and Kanayannur $(2 ; 13.33 \%)$ contributed patients to the series. In this study all the patients from the Alappuzha district were from Cherthala taluk $(6 ; 40 \%)$. Mukundapuram taluk of Thrissur district contributed one case $(6.67 \%)$ to the series.

\begin{tabular}{|c|c|c|c|c|c|c|}
\hline \multirow[t]{2}{*}{ Gender } & \multicolumn{6}{|c|}{$\begin{array}{c}\text { Age-Gender Distribution of Cases } \\
\text { Age Group (in Yrs) }\end{array}$} \\
\hline & $\begin{array}{c}\text { 11-20 } \\
\text { Number } \\
(\%)\end{array}$ & $\begin{array}{c}\mathbf{2 1 - 3 0} \\
\text { Number } \\
(\%)\end{array}$ & $\begin{array}{c}\text { 31-40 } \\
\text { Number } \\
(\%)\end{array}$ & $\begin{array}{c}\mathbf{4 1 - 5 0} \\
\text { Number } \\
(\%)\end{array}$ & $\begin{array}{c}\mathbf{5 1 - 6 0} \\
\text { Number } \\
(\%)\end{array}$ & $\begin{array}{c}\text { Total } \\
\text { Number } \\
(\%)\end{array}$ \\
\hline Male & $3(20)$ & $3(20)$ & $2(13.33)$ & $2(13.33)$ & $2(13.33)$ & $12(80)$ \\
\hline Female & $0(0)$ & $1(6.67)$ & $2(13.33)$ & $0(0)$ & $0(0)$ & $3(20)$ \\
\hline Total & $3(20)$ & $4(26.67)$ & $4(26.67)$ & $2(13.33)$ & $2(13.33)$ & $15(100)$ \\
\hline \multicolumn{7}{|c|}{ Rhinosporidiosis case distribution among rural and urban areas } \\
\hline \multicolumn{3}{|c|}{ Rural/Urban } & \multicolumn{2}{|l|}{ District } & \multicolumn{2}{|c|}{ Total number $(\%)$} \\
\hline \multicolumn{3}{|c|}{ Ernakulam } & Alappuzha & \multicolumn{2}{|c|}{ Thrissur } & \\
\hline \multicolumn{2}{|c|}{ Urban } & $6(40)$ & $2(13.33)$ & 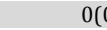 & \multicolumn{2}{|r|}{$8(53.33)$} \\
\hline \multicolumn{2}{|c|}{ Semiurban } & $1(6.67)$ & $0(0)$ & 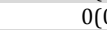 & \multicolumn{2}{|r|}{$1(6.67)$} \\
\hline \multirow{2}{*}{\multicolumn{2}{|c|}{ Rural }} & $1(6.67)$ & $4(26.67)$ & $1(6$. & \multicolumn{2}{|r|}{$6(40)$} \\
\hline & & $8(53.33)$ & $6(40)$ & $1(6$. & & $15(100)$ \\
\hline \multicolumn{7}{|c|}{ Taluk and district wise case distribution } \\
\hline \multicolumn{2}{|c|}{ District } & Taluk & \multicolumn{2}{|c|}{ Number $(\%)$} & \multicolumn{2}{|c|}{ Total number (\%) } \\
\hline \multirow{3}{*}{\multicolumn{2}{|c|}{ Ernakulam }} & Kochi & \multicolumn{2}{|c|}{$3(20)$} & \multirow{3}{*}{\multicolumn{2}{|c|}{$8(53.33)$}} \\
\hline & & Paravoor & \multirow{2}{*}{\multicolumn{2}{|c|}{$\begin{array}{c}3(20) \\
2(13.33)\end{array}$}} & & \\
\hline & & anayannur & & & & \\
\hline \multicolumn{2}{|c|}{ Alappuzha } & Cherthala & \multirow{2}{*}{\multicolumn{2}{|c|}{$\begin{array}{l}6(40) \\
1(6.67)\end{array}$}} & \\
\hline \multicolumn{2}{|c|}{ Thrissur } & zundapuram & & & \multicolumn{2}{|r|}{$1(6.67)$} \\
\hline
\end{tabular}

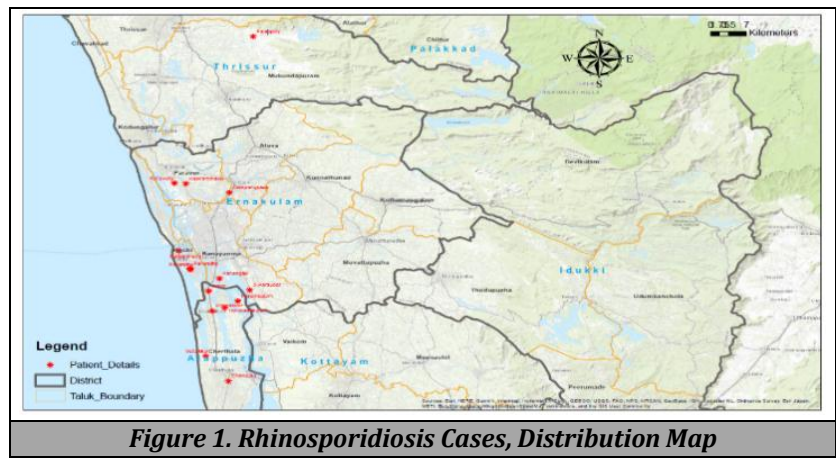

All the patients $(100 \%)$ gave a history of bathing in stagnant water ponds, backwater lakes, reservoir tanks, and quarry ponds. None of the patients gave a history of nosepicking. (Table: 2 )

\begin{tabular}{|ccc|}
\hline History & Yes & No \\
Bathing in water bodies & Number (\%) & Number (\%) \\
Nose picking & $15(100)$ & $0(0)$ \\
\hline & $0(0)$ & $15(100)$ \\
\hline
\end{tabular}

As depicted in Table: 3 , the most common symptoms in this series were nasal obstruction $(12 ; 80 \%)$ followed by epistaxis $(7 ; 46.67 \%)$ and nasal mass $(4 ; 26.67 \%)$.

\begin{tabular}{|cc|}
\hline Symptoms & Number (\%) \\
Nasal block & $12(80)$ \\
Epistaxis & $7(46.67)$ \\
Nasal mass & $4(26.67)$ \\
Nasal discharge & $2(13.33)$ \\
Difficulty in breathing & $2(13.33)$ \\
Foreign body sensation in throat & $2(13.33)$ \\
Headache/facial pain & $2(13.33)$ \\
Mouth breathing & $2(13.33)$ \\
Snoring & $2(13.33)$ \\
Change in voice & $1(6.67)$ \\
Postnasal discharge & $1(6.67)$ \\
Difficulty in swallowing & $1(6.67)$ \\
Throat pain & $1(6.67)$ \\
Decreased sense of smell & $1(6.67)$ \\
Watering from eye & $1(6.67)$ \\
\hline Table 3. Symptoms of Patients with Rhinosporidiosis
\end{tabular}

All cases in the series involved either nose, nasopharynx or both. As seen in Table: 4, most of the cases in the series affected both nose and nasopharynx $(7 ; 46.67 \%)$, only the nose was involved in $40 \%$ of cases (6). Nasopharynx alone was involved in $13.33 \%$ of cases (2).

The majority of the rhinosporidial masses in the series were unilateral $(13 ; 86.67 \%)$. They were seen more in the left nasal cavity $(8 ; 53.33 \%)$ than in the right $(5 ; 33.33 \%)$. In one case $(6.67 \%)$, both sides were affected, while in another (6.67\%), the attachment was central.

Most of the cases had pedunculated mass $(7 ; 46.67 \%)$. $40 \%$ had sessile masses ( 6 cases). $13.33 \%$ ( 2 cases) had both pedunculated and sessile masses.

\begin{tabular}{|cc|}
\hline Sites of Involvement & Number (\%) \\
\hline Nose & $6(40)$ \\
Nose-nasopharynx & $7(46.67)$ \\
Nasopharynx & $2(13.33)$ \\
Total & $15(100)$ \\
Laterality & Number (\%) \\
Unilateral & $13(86.67)$ \\
Bilateral & $1(6.67)$ \\
Central & $1(6.67)$ \\
Total & $\mathbf{1 5}(\mathbf{1 0 0})$ \\
Side & Number \\
Left & $8(53.33)$ \\
Right & $5(33.33)$ \\
Bilateral & $1(6.67)$ \\
Central & $1(6.67)$ \\
Total & $15(100)$ \\
\hline Type of Attachment & Number (\%) \\
Pedunculated & $7(46.67)$ \\
Sessile & $6(40)$ \\
Total & $2(13.33)$ \\
\hline Table 4. Rhinosporidial Mass Characteristics \\
\hline
\end{tabular}

As seen in Table: 5, among the 15 cases in the series, the majority of the rhinosporidial masses had attachments to more than one site $(24 ; 80 \%)$. Only $20 \%$ (6) of the attachments were single. $73.33 \%$ of these attachments were in the nasal cavity (22), while $26.67 \%$ of the attachments were in the nasopharynx (8).

The most common sites of attachment were in the inferior meatus and floor of the nasal cavity $(6 ; 24 \%)$ each.

Among the attachments in the nasal cavity, the most common sites were the inferior meatus and floor of the nasal cavity, followed by the nasal septum and the inferior turbinate. The least common sites of attachment in the series were the nasal vestibule and lateral wall of the nose.

The most common attachments in the nasopharynx were in the posterior wall and on the nasopharyngeal surface of the soft palate. The next commonest site of attachment was at the eustachian tubal orifice.

\begin{tabular}{|c|c|c|c|}
\hline \multicolumn{4}{|c|}{ Single vs Multiple } \\
\hline \multicolumn{2}{|c|}{ Attachments } & \multicolumn{2}{|c|}{ Number (\%) } \\
\hline \multicolumn{2}{|c|}{ Single } & \multicolumn{2}{|c|}{$6(20)$} \\
\hline \multicolumn{2}{|c|}{ Multiple } & \multicolumn{2}{|c|}{$24(80)$} \\
\hline \multicolumn{2}{|c|}{ Total } & \multicolumn{2}{|c|}{$30(100)$} \\
\hline \multicolumn{4}{|c|}{ Site of attachment- Nose and nasopharynx } \\
\hline $\begin{array}{c}\text { Site of } \\
\text { attachment }\end{array}$ & & $\begin{array}{c}\text { Number } \\
(\%)\end{array}$ & $\begin{array}{c}\text { Total number } \\
\text { (\%) }\end{array}$ \\
\hline \multirow{6}{*}{ Nose } & Inferior meatus & $6(20)$ & \multirow{6}{*}{$22(73.33)$} \\
\hline & Floor & $6(20)$ & \\
\hline & Septum & $3(10)$ & \\
\hline & Inferior turbinate & $3(10)$ & \\
\hline & Vestibule & $2(6.67)$ & \\
\hline & Lateral wall of the nose & $2(6.67)$ & \\
\hline \multirow{3}{*}{ Nasopharynx } & Posterior wall & $3(10)$ & \multirow{3}{*}{$8(26.67)$} \\
\hline & $\begin{array}{l}\text { Nasopharyngeal surface } \\
\text { of soft palate }\end{array}$ & $3(10)$ & \\
\hline & Eustachian tube orifice & $2(6.67)$ & \\
\hline Total & & & $30(100)$ \\
\hline
\end{tabular}


As shown in Table 6: among the 15 cases in the series, only $46.67 \%$ were primary (7). $53.33 \%$ of the cases (8) in the series were recurrent cases and had been operated elsewhere. $26.67 \%$ (4) in the series were second recurrences, while $20 \%$ (3) were third recurrences. One case $(6.67 \%$ ) in the series was the fifth recurrence.

None of these cases in the series, which underwent surgical excision and electrocautery of the base showed any recurrence throughout the entire follow-up period.

As can be seen in Table 6: among the 8 recurrent cases, $62.5 \%$ (5 cases) had defects in the nasal cavity due to repeated surgeries. These included -nasal synechiae $(3 ; 60 \%)$, destruction of the posterior end of the nasal septum $(1 ; 20 \%)$, and destruction of the lateral wall $(1 ; 20 \%)$.

Table: 6 shows that, among the 15 cases, 8 (53.33\%) had $\mathrm{O}^{+}$blood group, followed by $\mathrm{A}+$ and $\mathrm{B}+$ with 3 cases $(20 \%)$, with $1 \mathrm{~B}$ - case $(6.67 \%)$.

\begin{tabular}{|c|c|c|c|}
\hline \multicolumn{4}{|c|}{ Rhinosporidial Mass- Primary and Recurrent cases } \\
\hline \multicolumn{2}{|c|}{ Primary /Recurrent cases } & Number (\%) & Number (\%) \\
\hline \multicolumn{2}{|r|}{ Primary } & & $7(46.67)$ \\
\hline \multirow[t]{3}{*}{ Recurrent cases } & $2^{\text {nd }}$ Recurrence & $4(26.67)$ & \\
\hline & $3^{\text {rd }}$ Recurrence & $3(20)$ & $8(53.33)$ \\
\hline & $5^{\text {th }}$ Recurrence & $1(6.67)$ & \\
\hline \multicolumn{3}{|l|}{ Total } & $15(100)$ \\
\hline \multicolumn{4}{|c|}{ Sequelae of surgery } \\
\hline \multicolumn{2}{|c|}{ Defect in the nasal cavity } & \multicolumn{2}{|c|}{ Number (\%) } \\
\hline \multicolumn{2}{|c|}{ Synechiae } & \multicolumn{2}{|c|}{$3(60)$} \\
\hline \multirow{2}{*}{\multicolumn{2}{|c|}{$\begin{array}{l}\text { Lateral wall destruction } \\
\text { Septum posterior end-destruction }\end{array}$}} & \multicolumn{2}{|c|}{$1(20)$} \\
\hline & & \multicolumn{2}{|c|}{$1(20)$} \\
\hline \multicolumn{4}{|c|}{ Blood group } \\
\hline \multicolumn{2}{|r|}{ Blood group } & \multicolumn{2}{|c|}{ Number (\%) } \\
\hline \multicolumn{2}{|r|}{$0+$} & \multicolumn{2}{|c|}{$8(53.33)$} \\
\hline \multicolumn{2}{|r|}{ A+ } & \multicolumn{2}{|c|}{$3(20)$} \\
\hline \multicolumn{2}{|r|}{$\mathrm{B}+$} & \multicolumn{2}{|c|}{$3(20)$} \\
\hline \multicolumn{2}{|r|}{ B - } & \multicolumn{2}{|c|}{$1(6.67)$} \\
\hline \multicolumn{2}{|r|}{ Total } & \multicolumn{2}{|c|}{$15(100)$} \\
\hline \multicolumn{4}{|c|}{$\begin{array}{l}\text { Table 6. Rhinosporidial Mass-Recurrence, Sequelae of Surgery and } \\
\text { Blood Group }\end{array}$} \\
\hline
\end{tabular}

\section{DISCUSSION}

The present study shows that rhinosporidiosis is found more commonly among males when compared to females. (M: F 4:1). This is in agreement with most of the studies. ${ }^{8,9}$ The lesser prevalence among females could be due to a lesser chance of animal contact and lesser frequent pond baths. ${ }^{10}$ Typically, young and middle-aged persons are affected by rhinosporidiosis. In this study, the disease was predominantly found in the 21-40 year age groups, as seen in other series. ${ }^{8,11,12}$

Rhinosporidiosis mainly affects farmers, manual labourers and students. Some studies have observed a higher incidence among tribal populations also.13,14 Frequently people of lower socioeconomic status are afflicted by this disease.8,11 All the patients in this series gave a history of bathing in ponds, lakes and reservoirs as in most of the series. ${ }^{12,14}$

All individuals exposed to the same environment do not get infected. Spores do not enter the intact epithelium and a breach in epithelial continuity is necessary to enable infection. History of nose picking and trauma were reported in a prominent study. ${ }^{3}$ All the patients who were admitted to the hospital had been asked about the habit of nose-picking, though none of them volunteered to divulge information regarding it probably because it is considered as socially inappropriate behaviour.
Results of the present study reaffirmed the endemic nature of rhinosporidiosis in Kerala's Central district of Ernakulam and the adjoining parts of Alappuzha and Thrissur. The average number of cases per year was 6 . Recent studies from Kerala's Northern district of Malappuram showed a higher rate of 15.4 per year. ${ }^{10}$

The map shows the maximum clustering of cases in the backwater region of the adjacent districts of Ernakulam and Alappuzha. A study from the Malappuram district has identified the specific taluks with a higher incidence of the disease. ${ }^{10}$

In this series, the majority (53.33\%) of the patients hailed from urban areas. Only $40 \%$ came from rural areas. This is in contrast to most of the previous studies, which state that the disease is common in rural areas.9,11,15 Kerala's urban population had increased by $92.72 \%$ in the decade from 2001-2011. Ernakulam, from where the majority of the patients hail, is the most urbanised district $(68.07 \%)$ of Kerala, with the maximum percentage of the population $(96.19 \%)$ covered by the water supply schemes, compared to the other districts of Kerala. 16

The reduced number of cases in this study, when compared to similar studies from Kerala, might be due to the rapid urbanisation of the district, the increased supply of piped water at homes and decreasing usage of ponds for bathing. Karthikeyan et al. have also reported the drastic reduction in the number of patients of rhinosporidiosis presenting per year in Pondicherry. ${ }^{9}$ He attributes this to the strong public health education program in the area which may have dissuaded the new generation of the rural population in the region from high-risk activities associated with this infection like pond bathing.

Nevertheless, an active public health intervention should be made to identify the water bodies contaminated with endospores of Rhinosporidium spores and to create awareness among the public against taking baths in these water bodies.

In this study, an attempt has been made to identify the taluks, the administrative subunits of the district, from which most of the rhinosporidiosis cases come.

The most common symptoms in this series were nasal obstruction, followed by epistaxis and nasal mass. This is similar to the findings of many studies. ${ }^{9,15}$ However, in some of the studies, epistaxis was the predominant symptom. ${ }^{11}$

In the present study, the rhinosporidial masses were seen mostly in the left nasal cavity, followed by the right. This is in contrast to the study by Manonmany et al. ${ }^{12}$ in which, a higher incidence was seen on the right (47\%) than the left (33\%), while in another series no predilection to any side of the nose was noted. ${ }^{15}$

In the current study, the nasal cavity and nasopharynx together constituted the most common sites. This was followed by mass limited only to the nasal cavity and nasopharynx alone. Most of the studies have reported the nasal cavity as the most frequently affected site, followed by the nasopharynx.9,11,14,17,18 In the series of Manonmany et al. ${ }^{12}$ the most commonly affected site was the nose, followed by the oropharynx.

Rhinosporidiosis can affect more than one site. These include buccal cavity, parotid, soft palate, paranasal sinuses, conjunctivae, eyes, lacrimal sac, nasolacrimal duct, larynx, trachea, urethra, penis, skin, bone and muscles. In some 
series, the dissemination of the disease to the limbs, trunk and viscera is also described. . $^{911,14,17,18}$

Most of the rhinosporidial masses in this series had multiple attachments, with the great majority of them being in the nasal cavity. In this series, the most common sites of attachment of the rhinosporidial masses in the nasal cavity were the inferior meatus and floor of the nasal cavity, followed by the nasal septum and the inferior turbinate, and nasal vestibule and the lateral nasal wall of the nose.

Similar findings were noted in other studies also. ${ }^{10,19}$ In a series of 78 cases, Rajendran et al. observed that the posterior lip of the valve of Hasner in the inferior meatus was the commonest site of attachment. ${ }^{20}$

In the study by Varghese et al. it was found that an independent significant factor for recurrence is the involvement of more than two sites. Previous surgery and involvement of sites like nasal septum, middle turbinate, nasopharynx and posterior pharyngeal wall also carry a significant chance for recurrence. ${ }^{21}$

Most of the rhinosporidial masses in this series were pedunculated, rather than sessile masses. A similar observation was made in the series of Manonmany et al. ${ }^{12}$ However, in another series sessile masses predominated. ${ }^{10}$

Blood grouping is usually done in cases of rhinosporidiosis in anticipation of the increased bleeding during surgical excision. Data regarding blood groups is studied in most of the series on rhinosporidiosis. Rhinosporidiosis was more common among blood group 0 (70\%), followed by blood group $\mathrm{AB}$ in the study by Kameswaran et al. ${ }^{22}$ In the series of Vadakkan et al. maximum number of cases of Rhinosporidiosis were seen among blood group 0 (75\%), followed by blood group A (20\%). ${ }^{22}$ However, Manomany et al. reported the maximum number of cases among $\mathrm{B}+$, followed by the $0+$ blood group. ${ }^{12}$ Mathew et al. reported the highest incidence among $\mathrm{O}+$ followed equally by $\mathrm{A}+, \mathrm{B}+$ and $\mathrm{AB}+.^{15}$ In the present series also, a maximum number of cases were seen among blood group $0+$ followed equally by $\mathrm{A}+\mathrm{B}+$ blood groups. Among the recurrent cases in the series, which had been operated elsewhere, blood group $0+$ predominated.

All the cases in the series which underwent surgical excision and follow up, were symptom-free during the one year follow up period.

The recurrent cases in this series had been operated elsewhere. Most of them were second recurrences. Considerable damage to the nasal mucosa and structures was seen in cases that underwent repeated surgeries, the most common being nasal synechiae. Destruction of the lateral wall of the nose and posterior end of the nasal septum was seen in the cases that underwent repeated surgeries. $13 \%$ of the recurrent cases in the series required blood transfusion.

\section{CONCLUSIONS}

Rhinosporidiosis is a chronic disease afflicting people of low socioeconomic status who are in contact with stagnant water in endemic areas. Young males from urban areas are mostly affected. $0+$ blood group is commonly associated with the disease. The most frequent complaints are nasal obstruction and epistaxis. The nose and nasopharynx are the usual sites involved. The inferior meatus and floor of the nasal cavity are the common sites of attachment in the nose. The recurrent disease produces considerable financial and mental strain to the patient and family. Recurrence can be minimised with careful and complete endoscope-guided removal under general anaesthesia. Regular postoperative follow-up with endoscopy should be done to identify and treat the recurrences at the earliest. Public health education should be accelerated in the endemic areas and the population should be cautioned against taking dip baths in the contaminated water bodies.

Data sharing statement provided by the authors is available with the full text of this article at jemds.com.

Financial or other competing interests: None.

Disclosure forms provided by the authors are available with the full text of this article at jemds.com.

The study was conducted utilising the SBMR fund for research project 2017.

I would like to thank Mr Meharaj S, Senior Account Manager, NeST Technologies for assistance in preparing Rhinosporidiosis diseasedistribution map. I would like to thank Dr Sanu. P. Moideen Department of ENT and Head and Neck Surgery, MOSC Medical College, Kolenchery for the assistance in drafting the manuscript.

Compliance with ethical standards: Anonymity of the patients whose details were collected for the study were maintained

\section{REFERENCES}

[1] Lakshmanan M, Kameswaran S, Jayapal JI. Histochemistry of Rhinosporidium seeberi. In Proceedings of the International Symposium of Taxonomy of Fungi: Chennai, India 1973.

[2] Töz S. Rhinosporidium seeberi: is it a fungi or parasite? Turkiye Parazitol Derg 2020;44(4):258-60.

[3] Karunaratne WAE: The pathology of rhinosporidiosis. J Path Bact 1934;XLII:193-202.

[4] Herr RA, Mendoza L, Arseculeratne SN, et al. Immunolocalization of an endogenous antigenic material of Rhinosporidium seeberi expressed only during mature sporangial development. FEMS Immunol Med Microbiol 1999;23(3):205-12.

[5] Jayasekera S, Arseculeratne SN, Atapattu DN, et al. Cellmediated immune responses (CMIR) to Rhinosporidium seeberi in mice. Mycopathologia 2001;152(2):69-79.

[6] Arseculeratne SN. Chemotherapy of rhinosporidiosis: a review. J Infect Dis Antimicrob Agents 2009;26(1):21-7.

[7] Ashworth JH, Turner AL. A case of rhinosporidiosis. The Journal of Laryngology \& Otology 1923;38(6):285-99.

[8] Sinha A, Phukan JP, Bandyopadhyay G, et al. Clinicopathological study of rhinosporidiosis with special reference to cytodiagnosis. J Cytol 2012;29(04):246-9.

[9] Karthikeyan P, Vijayasundaram S, Pulimoottil DT. A retrospective epidemiological study of rhinosporidiosis in a rural tertiary care centre in Pondicherry. J Clin Diagn Res 2016;10(5):MC04-8.

[10] Ahmed NA, Mohammed S, Raj G. Rhinosporidiosis: an epidemiological study. Journal of Evolution of Medical and Dental Sciences 2013;2(38):7227-34.

[11] Guru RK, Pradhan DK. Rhinosporidiosis with special reference to extra nasal presentation. Journal of 
Evolution of Medical and Dental Sciences 2014;3(22):6189-200.

[12] Manonmany S, Renjit RE, Philip JT, et al. Rhinosporidiosis: analysis of cases presenting to a tertiary care hospital in rural Kerala. Int J Biomed Res 2015;6(6):416-20.

[13] Kumari SK, Uma P, Ramesh S, et al. Prevalence of rhinosporidiosis in Srikakulam District. Journal of Evolution of Medical and Dental Sciences 2015;4(50):8685-90.

[14] Sengupta S, Pal S, Biswas BK, et al. Clinicopathological study of 273 cases of rhinosporidiosis over a period of ten years in a tertiary care institute catering predominantly rural population of tribal origin. Bangladesh Journal of Medical Science 2015;14(2):15964.

[15] Mathew S, Arora RD, Prabha N, et al. Retroanalytical Study of Epidemiological Factors of Rhinosporidiosis. Int Arch Otorhinolaryngol 2021;25(4):e504-8.

[16] Maneesh P. Access to water and drinking water supply coverage: understanding water security in Kerala. Indian Journal of Economics and Development 2015;3(9):1-6.

[17] Arseculeratne SN. Recent advances in rhinosporidiosis and Rhinosporidium seeberi. Indian J Med Microbiol 2002;20(3):119-31.
[18] Bandopadhyay SN, Jana U, Bandyopadhyay G, et al. Rhinosporidiosis: various presentations and different sites. Bengal J Otolaryngol Head Neck Surg 2015;23(2):48-56.

[19] Chakraborty D, Das C, Hansda R. Three years' experience of management of different types of rhinosporidiosis in rural part of western West Bengal. Bengal Journal of Otolaryngology and Head Neck Surgery 2015;23(3):92-8.

[20] Rajendran S, Ashok SS, Ramkumar T. Primary nasal rhinosporidiosis - a ten year multicentre experience: what we know? Int J Otorhinolaryngol Head Neck Surg 2020;6(2):343-6.

[21] Varghese L, Kurien R, Susheel S, et al. RhinosporidiosisFactors predicting disease recurrence. Mycoses 2021;64(12):1471-9.

[22] Kameswaran S, Lakshmanan M. Rhinosporidiosis. In: Kameswaran S, Kameswaran M, eds. ENT disorders in a tropical environment. Chennai: MERF Publications 1999:19-34.

[23] Vadakkan JR, Ganeshbala A, Jalagandesh B. A clinical study of rhinosporidiosis in rural coastal population: our experience. Journal of Evolution of Medical and Dental Sciences 2014;3(51):11938-43. 